Supporting Information

\title{
Salicylanilides reduce SARS-CoV-2 replication and suppress induction of inflammatory cytokines in a rodent model
}

Steven Blake, ${ }^{1+}$ Namir Shaabani, ${ }^{2,+}$ Lisa M. Eubanks, ${ }^{1}$ Junki Maruyama, ${ }^{3}$ John T. Manning, ${ }^{3}$ Nathan Beutler, ${ }^{2}$ Slobodan Paessler, ${ }^{3}$ Henry Ji, ${ }^{4}$ John R. Teijaro ${ }^{2}$ and Kim D. Janda ${ }^{*}$

\section{Affiliations:}

${ }^{1}$ Departments of Chemistry and Immunology, The Skaggs Institute for Chemical Biology, Worm Institute of Research and Medicine (WIRM), The Scripps Research Institute, 10550 North Torrey Pines Road, La Jolla, California 92037, United States.

2Department of Immunology and Microbiology, The Scripps Research Institute, 10550 North Torrey Pines Road, La Jolla, California 92037, United States.

${ }^{3}$ Department of Pathology, University of Texas Medical Branch, 301 University Blvd, Galveston, Texas 77555, United States.

${ }^{4}$ Sorrento Therapeutics Inc., 4955 Directors Place, San Diego, California 92121, United States.

*Corresponding author e-mail: kdjanda@scripps.edu 


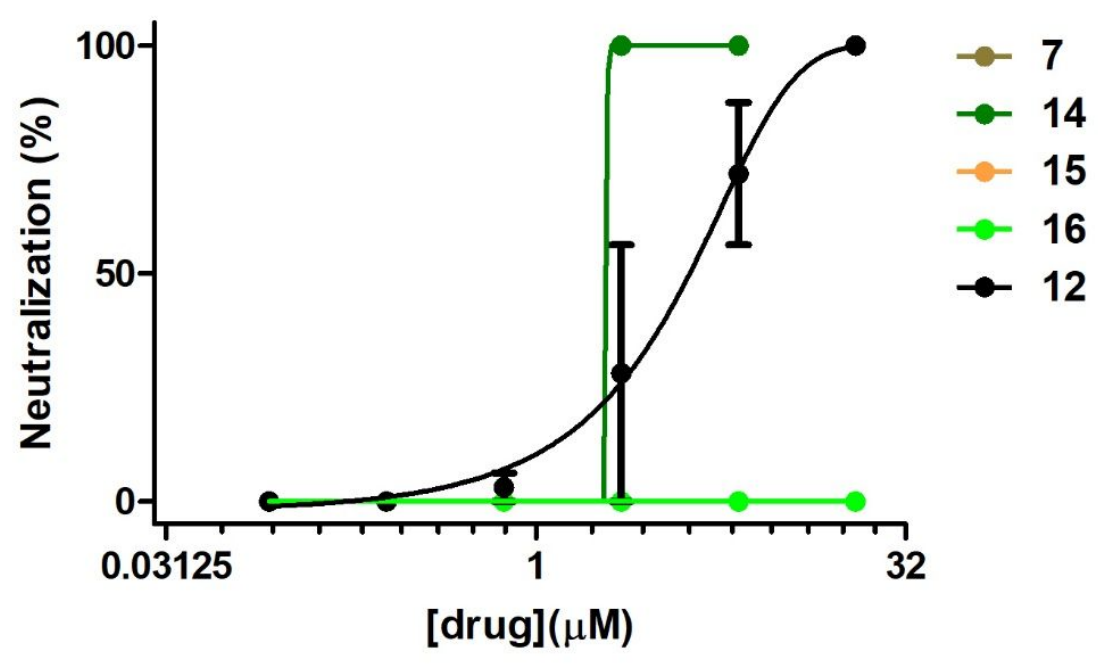

Figure S1-Sn. Graph illustrating percent neutralization of viral activity in Vero cells. 


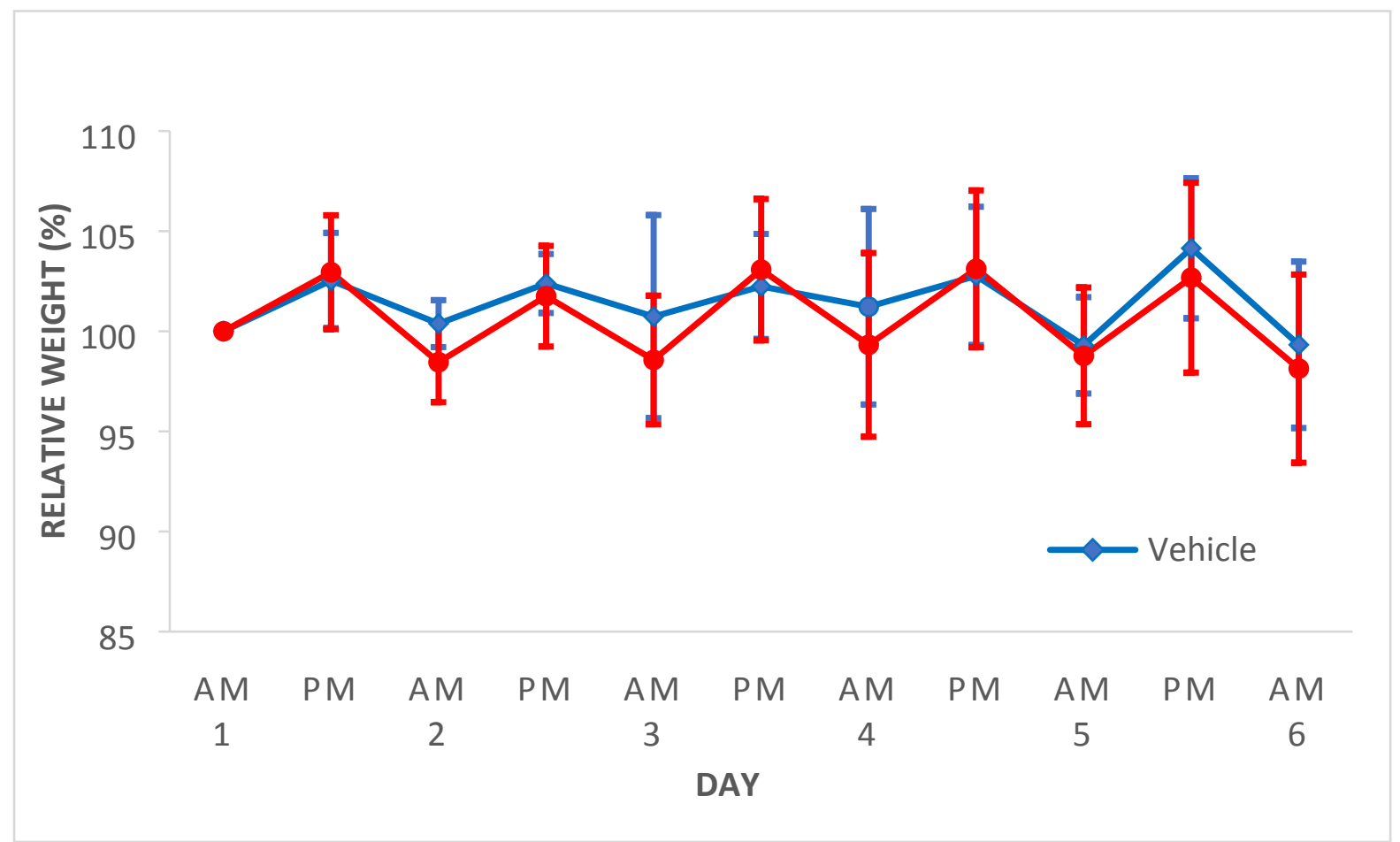

Figure S2-Sn. Graph depicting relative body weight of non-infected mice given either vehicle or 11 over 5 days 